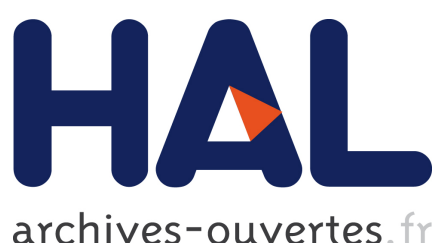

archives-ouvertes

\title{
A Feature-based Survey of Model View Approaches
}

\author{
Hugo Bruneliere, Erik Burger, Jordi Cabot, Manuel Wimmer
}

\section{To cite this version:}

Hugo Bruneliere, Erik Burger, Jordi Cabot, Manuel Wimmer. A Feature-based Survey of Model View Approaches. ACM/IEEE 21th International Conference on Model Driven Engineering Languages and Systems (MODELS '18), Oct 2018, Copenhagen, Denmark. ACM/IEEE 21th International Conference on Model Driven Engineering Languages and Systems (MODELS '18), pp.211-211, $<10.1145 / 3239372.3242895>$. $<$ hal-01891295>

\section{HAL Id: hal-01891295 \\ https://hal.archives-ouvertes.fr/hal-01891295}

Submitted on 9 Oct 2018

HAL is a multi-disciplinary open access archive for the deposit and dissemination of scientific research documents, whether they are published or not. The documents may come from teaching and research institutions in France or abroad, or from public or private research centers.
L'archive ouverte pluridisciplinaire HAL, est destinée au dépôt et à la diffusion de documents scientifiques de niveau recherche, publiés ou non, émanant des établissements d'enseignement et de recherche français ou étrangers, des laboratoires publics ou privés. 


\title{
A Feature-based Survey of Model View Approaches
}

\author{
Extended Abstract ${ }^{*}$
}

\author{
Hugo Bruneliere \\ IMT Atlantique - LS2N (CNRS) \& ARMINES \\ Nantes, France \\ hugo.bruneliere@imt-atlantique.fr \\ Jordi Cabot \\ ICREA \& Universitat Oberta de Catalunya (UOC) \\ Barcelona, Spain \\ jordi.cabot@icrea.cat
}

\section{CCS CONCEPTS}

- Software and its engineering $\rightarrow$ Model-driven software engineering; Abstraction, modeling and modularity;

\section{KEYWORDS}

Modeling, Viewpoint, View, Model, Survey

\section{ACM Reference Format:}

Hugo Bruneliere, Erik Burger, Jordi Cabot, and Manuel Wimmer. 2018. A Feature-based Survey of Model View Approaches: Extended Abstract. In ACM/IEEE 21th International Conference on Model Driven Engineering Languages and Systems (MODELS '18), October 14-19, 2018, Copenhagen, Denmark. ACM, New York, NY, USA, 1 page. https://doi.org/10.1145/3239372. 3242895

When dealing with complex software systems, models that conform to different modeling languages are used to describe these systems from various perspectives. This is even more prevalent for Systems of Systems and Cyber-Physical Systems, because of multi-disciplinary co-engineering processes. Such situations often lead to information scattering across many heterogeneous and interconnected models, or to overlappings and redundancies that may create inconsistencies in system descriptions. Thus, engineers may have difficulties to efficiently comprehend the studied systems as they need to explore all these models in full detail.

View-based approaches in software engineering have been proposed to tackle these issues. They mostly follow a strategy of proposing a fixed set of predefined viewpoints to be used in different application domains or scenarios. This offers several advantages such as improved understanding, or more integrated and comprehensive tool support. However, these approaches lack the flexibility required in many scenarios where the useful model views go beyond a limited set of viewpoints, and may change over time as the development process moves on.

*The full version of this SoSyM journal paper is available from https://link.springer com/article/10.1007/s10270-017-0622-9

MODELS '18, October 14-19, 2018, Copenhagen, Denmark

(c) 2018 Association for Computing Machinery.

This is the author's version of the work. It is posted here for your personal use. Not for redistribution. The definitive Version of Record was published in ACM/IEEE 21th International Conference on Model Driven Engineering Languages and Systems (MODELS '18), October 14-19, 2018, Copenhagen, Denmark, https://doi.org/10.1145/ 3239372.3242895 .

\author{
Erik Burger \\ Karlsruhe Institute of Technology (KIT) \\ Karlsruhe, Germany \\ burger@kit.edu \\ Manuel Wimmer \\ CDL-MINT, TU Wien \\ Vienna, Austria \\ wimmer@big.tuwien.ac.at
}

Recent advances in model-based engineering have fostered the possibility of having more flexible view-based approaches, based on metamodeling and model transformation techniques for instance. These model view approaches typically support the creation of custom views over heterogeneous models. However they differ in their mechanisms to create such views (calculated on-demand, stored as separate models, etc.), the expressivity of the view definition language, the support for view updates, etc. Given the plethora of existing approaches-most of them only providing partial solutions-it is difficult to know how each approach compares to the others and what are their respective trade-offs. This makes it difficult to identify which one(s) may be better suited for given needs, thus hampering the usefulness of such model views approaches in practice.

In this paper, we provide orientation via an extended study of the state-of-the-art in the area of model viewpoints/views. We believe this research line is becoming more and more crucial not only for the modeling community, but also from a more general software and systems engineering perspective. Thus, we motivate why many future applications of modeling will depend, one way or the other, on some kind of mechanism for dealing with viewpoints/views on models. Furthermore, we describe what are the solutions available at the time of writing and how they currently compare to each other. To this intent, we categorize them according to a detailed feature model that aims to shed more light on this topic.

Finally, we propose a research agenda highlighting related challenges we have identified as important to tackle in the future. In addition to overall scalability issues, such challenges includes $(i)$ dealing with terminology problems that quite often hamper the combination and reuse of existing initiatives, (ii) addressing the well-know but still complex view updating problem(s), (iii) better supporting incremental view maintenance in the general case, (iv) improving the generation of adapted view concrete syntaxes, and $(v)$ working on security-related aspects (e.g., view access control).

This paper acts as an entry point for both academic researchers and industrial practitioners, and intends to trigger a broader discussion within the community. This should allow enriching our current feature model and extending the approach comparison in the future. Most importantly, we hope this work will raise the awareness on research challenges around viewpoints/views on models and their practical usages. 